\title{
Developing a Framework for Assessing Risks Associated with Human Responses in Emergency Escape on Offshore Installations
}

\author{
Norafneeza Norazahar*1,2, Arshad Ahmad ${ }^{1}$ \\ ${ }^{1}$ Centre of Hydrogen Energy, Institute of Future Energy, Universiti Teknologi Malaysia, 81310 Johor Bahru, \\ Johor, Malaysia \\ ${ }^{2}$ Faculty of Chemical and Energy Engineering, Universiti Teknologi Malaysia, 81310 Johor Bahru, Johor, \\ Malaysia \\ *Corresponding author: norafneeza@utm.my
}

\section{Article History}

Received: March 01, 2018

Received in revised form: May 14, 2018

Accepted: June 06, 2018

Published Online: July 30, 2018

\begin{abstract}
This paper presents a framework for assessing and managing risks of personnel responding to emergencies requiring escape on offshore installations. Personnel's action or response can be affected by human factors during the emergency escape. The framework has four categories: analyzing human factors in safety barriers for emergency escape, quantifying the failure probability of personnel's response, assessing risks associated with personnel's response, and managing the risk associated with personnel's response. The first category requires defining and arranging safety barriers for emergency escape based on the Swiss cheese model. Both second and third categories calculate the probability of personnel failing to respond to emergency escape using Bayesian analysis. A safety hierarchy for managing risks associated with personnel's response is introduced in the fourth category.
\end{abstract}

Keywords: Emergency escape, human factors, risk assessment, risk management, offshore installations.

\subsection{INTRODUCTION}

Activities of emergency escape on offshore installations expose personnel to a certain risk level and are dependent on their response to prevent themselves from the escalating emergency scenario. Ineffective personnel's responses could contribute to high level of risks. Ineffective personnel's responses could be caused by the presence of human factors in safety barriers and emergency escape plan.

Examples of these human factors include late activation of an emergency alarm, ineffective command and control, communication problems, inadequate refresher training, and insufficient training as a team on offshore installations [8, $7,2,22]$. The emergency escape during the Macondo blowout was unsuccessful due to the presence of human factors such as lack of emergency drills and exercises, poor emergency escape plan, and ineffective communication on emergency situation [19].

The presence of human factors in emergency escape on offshore installations has been studied by many researchers $[8,7$, 2, 22]. The researchers focused only on the estimation of human error probability (HEP) and risk analysis. DiMattia et al. [5] determined human error probabilities of escape and evacuation on offshore installations using a success likelihood index method (SLIM). Khan et al. [9] designed a tool known as human error probability index (HEPI) that uses SLIM to assess human errors during escape and evacuation on offshore platforms. Deacon et al. [4] developed a framework for calculating the human error probabilities for escape, evacuation, and rescue (EER) on offshore installations. Studies on human error probabilities are more relevant to a risk assessment of escape and evacuation on offshore installations. 


\subsection{PROBLEM STATEMENT}

Human factors and technical aspects can be integrated in the risk management of offshore installations [18]. The risk assessment and management of personnel's responses during emergency escape must include human factors. The challenge for assessing risks is to incorporate human factors into both qualitative and quantitative analyses. Human factors in the emergency escape plan such as poor communication and ineffective training are complicated to measure and assess.

The risk assessment and management for emergency escape are important to operators and personnel working on offshore installations. The risk assessment could inform the level of risks associated with personnel's responses that have been affected by human factors. The presence of human factors in safety barriers or emergency escape plan must be controlled or managed to improve the safety of emergency escape.

\subsection{OBJECTIVE}

The objective of this paper is to present the development of a framework consisting of risk assessment and management of personnel's response. The framework was developed to identify and assess human factors in safety barriers and the emergency escape plan of offshore installations [12]. The framework has risk management to manage or control the presence of human factors in emergency escape activities.

\subsection{SCOPE OF WORK}

This paper defines safety barriers for emergency scenarios requiring escape on offshore installations. Examples of safety barriers are evacuation procedures, the equipment used in the emergency escape, and personnel's responses or actions required during the emergency.

General evacuation procedures for emergency escape begin with alarms activation due to emergency scenarios such as hydrocarbon releases, man overboard, collisions involving vessels or helicopters, or fires and explosions. When the emergency alarm is activated, personnel are required to stop working and must move to escape routes leading to the designated muster station.

Equipment for emergency escape includes both audible and visible alarms. Proper communication regarding the emergency scenario is typically done using a public address (PA) system. Escape routes and muster station with proper signage and lighting are made available to direct individuals to temporary safe refuge.

This paper defines personnel's responses according to the general implementation of emergency escape on offshore installations [15]. Hear alarms and listen to announcement are two examples of personnel's responses in the event of emergency escape.

\subsection{DEVELOPMENT OF FRAMEWORK}

The framework of human factors risk assessment and management for emergency escape on offshore installations can be divided into to four categories:

i) Category 1 - Identifying human factors in safety barriers,

ii) Category 2 - Estimating the probability of personnel failing to respond,

iii) Category 3 - Assessing risks associated with personnel's responses, and

iv) Category 4 - Managing risks associated with personnel's responses in the emergency escape.

These four categories were designed to be dependent on each other. The details of each class are discussed in Section 5.1 to 5.4 .

\subsection{Category 1 - Identify Human Factors in Safety Barriers}

The development of framework begins with identifying the presence of human factors in safety barriers as illustrated in Fig. 1. Safety barriers consisting of evacuation procedures, equipment, and actions or responses are arranged using the Swiss cheese model [16]. The holes in the Swiss cheese represent the human factors in evacuation procedures, equipment, and actions or responses. The trajectory of human factors through the holes in every safety barrier can affect personnel performing the emergency escape. 
Identifying and addressing human factors in each safety barrier can be conducted in a qualitative manner. CAPP [3] and OGP [15] can be used as references for identifying the human factors in evacuation procedures and equipment. Blackman et al. [1] provided performance shaping factors that can be used as human factors affecting personnel's responses. Examples of human factors present in safety barriers are listed in Table 1. The application of Category 1 of the framework is illustrated in [10].

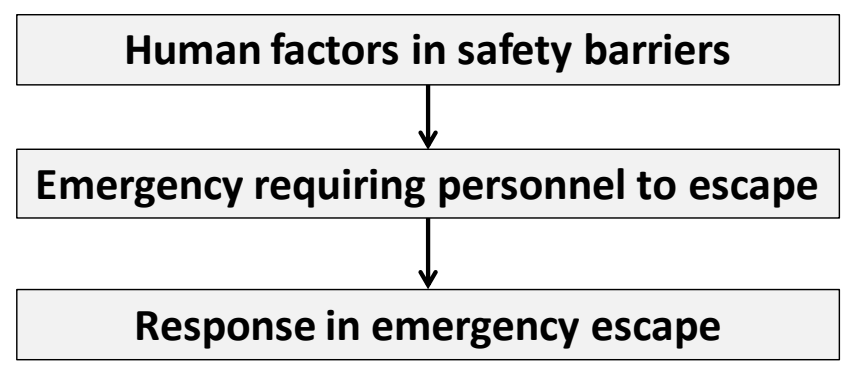

Figure 1. Procedures for identifying human factors

Table 1. Examples of human factors in the safety barriers of emergency escape

\begin{tabular}{ll}
\hline \multicolumn{1}{c}{ Safety Barriers } & \multicolumn{1}{c}{ Human Factors } \\
\hline Evacuation procedures & No communication to activate the emergency alarm \\
Equipment & No scheduled maintenance causes less effective alarm activation \\
Response or actions & Fatigue due to long hours of working [1] \\
\hline
\end{tabular}

\subsection{Category 2 - Estimate the Probability of Personnel Failing to Respond}

Fig. 2 shows the sequence for estimating the probability of personnel's responses considering human factors in the safety barrier. The study extends the framework to include a model for estimating the probability of personnel failing to respond to emergency escape. The objective of Category 2 is to determine the failure of personnel's responses that could have impact on the emergency escape.

The study used Bayesian analysis to determine the probability of failure of personnel's responses [17, 20, 21]. The analysis considers human factors in every safety barrier. The human factors in the evacuation procedures can be connected to equipment and personnel's responses following the safety barrier arrangement. The interaction of human factors in every safety barrier is used to develop conditional probability table (CPT). The output in the CPT refers to personnel's response in the event of emergency escape. The application of framework using the Bayesian analysis was discussed in [11].

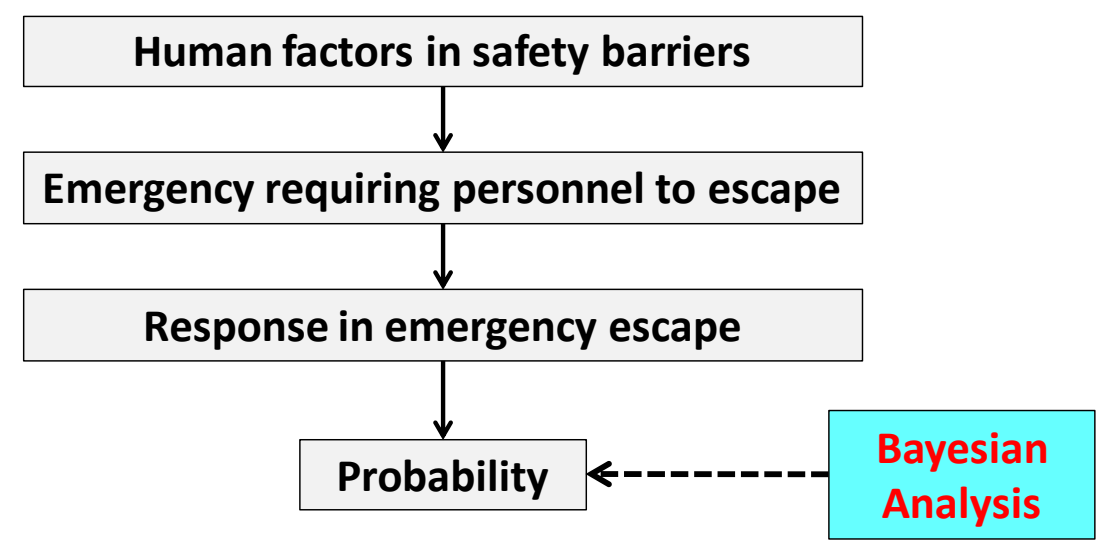

Figure 2. Procedures for estimating probability of personnel failing to respond 


\subsection{Category 3 - Assess Failures of Personnel's Responses}

The framework was then designed to assess risks associated with personnel's responses. Category 3 is an extension of the second part of the framework as shown in Fig. 3. It aims to analyze the probability and impacts of the failure of performing emergency escape considering the presence of human factors. Risks associated with personnel's responses were assessed by integrating the probability of failure and its consequences.

This paper considers hear the emergency alarm and listen to the announcement as personnel's responses. Based on the defined personnel's responses, two possible consequences of failing to respond are late arrival at the muster station and may involve in the escalating emergency scenario. Bayesian analysis can be used to quantify the consequence. The application of the framework in determining the consequences is demonstrated in [13].

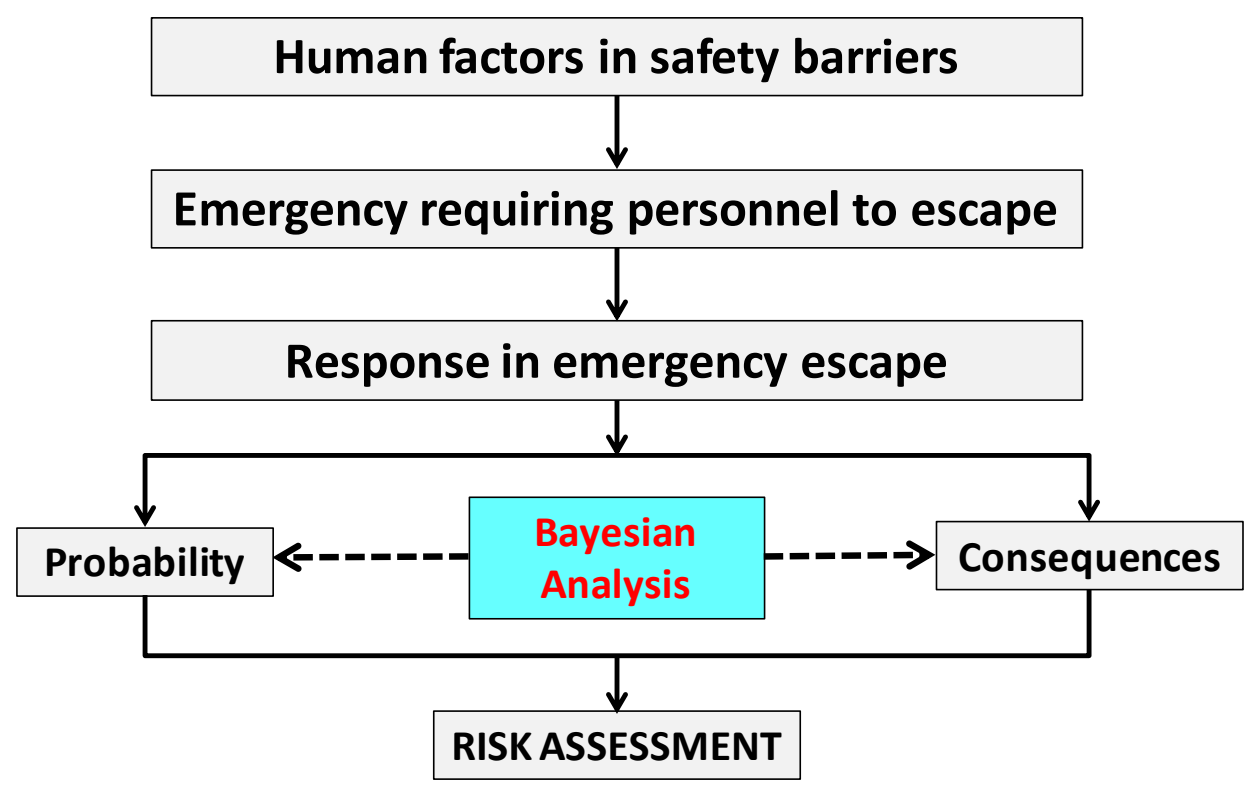

Figure 3. Procedures for assessing risks associated with personnel's response

\section{$5.4 \quad$ Category 4 - Manage the Risk}

Fig. 4 presents the fourth step of the framework, which completes the development of framework. The objective of Category 4 is to manage or minimize risks associated with personnel's responses affected by the presence of human factors. Norazahar et al. [14] presented the application of risk management of escape and evacuation on offshore installations.

Risk acceptance level was used to determine whether the risk is acceptable or not, according to the safety rules or operators of offshore installations. If the risk is low and acceptable to the operators and safety rules, the emergency escape is presumed to be safe for personnel. In the case of the risk is unacceptable, it must be minimized or managed using a safety hierarchy.

Fig. 5 introduces a safety hierarchy as a mechanism of risk management. The safety hierarchy has three safety steps: inherent safety, engineering safety, and procedural safety. Inherent safety measures consist of elimination and minimization of human factors, substitution of inefficient equipment, and simplification of evacuation procedures. Engineering safety requires adding safer equipment to the facilities provided for emergency on offshore installations. Two types of safer equipment are active and passive barriers. The purpose of engineering safety is to provide reliable safeguards for reducing risks associated with personnel's responses. Modifications or changes to equipment must be followed by updating rules and procedures to allow personnel to have a better understanding of hazards, equipment, procedures, human factors, and environmental conditions involved in emergency situations. 


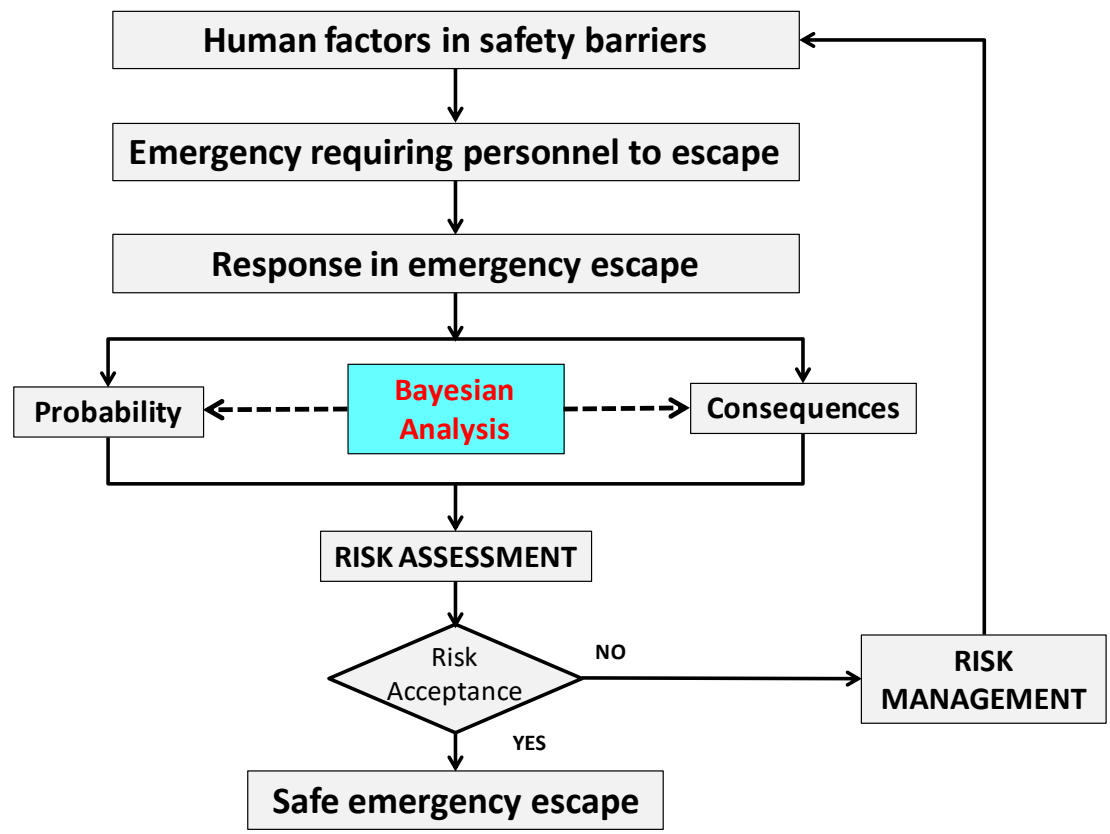

Figure 4. Framework for assessing and managing risks associated with personnel's responses

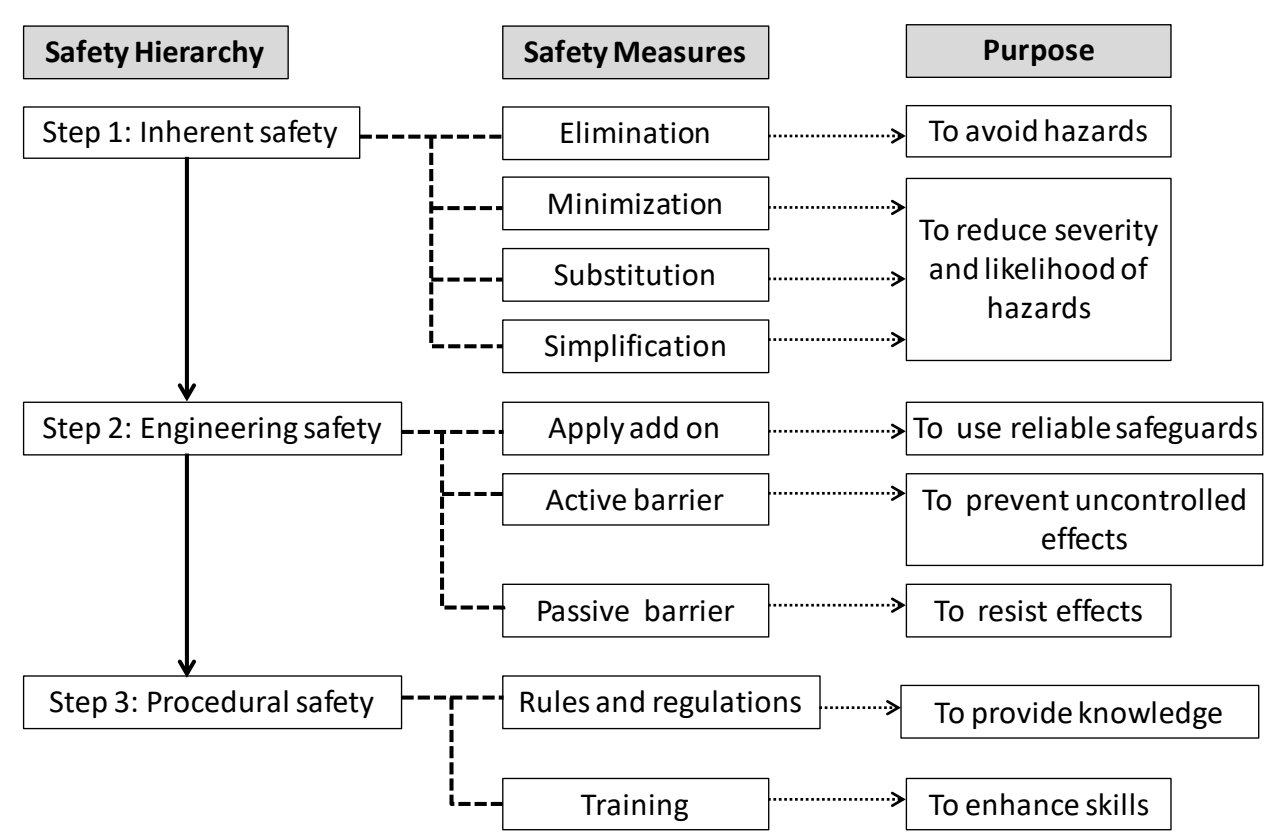

Figure 5. Safety hierarchy for managing risks

\subsection{CONCLUSION}

A framework was developed to assess and manage risks associated with personnel's responses during emergency escape on offshore installations. Human factors in safety barriers were identified using the Swiss cheese model. The human factors were connected to safety barriers, emergency scenarios, and personnel's response using Bayesian analysis, which could also quantify the probability of failures. Consequences of personnel failing to respond to emergency scenario were estimated based on the presence of human factors in safety barriers. The risk associated with personnel's responses can be managed or controlled using a safety hierarchy.

For future work, an experimental study of emergency escape considering the presence of human factors should be conducted. The experimental data could verify the practicality of the framework to offshore industry. 


\section{References}

[1] Blackman, H.S., Gertman, D.I., \& Boring, R.L. (2008). Human error quantification using performance shaping factors in the SPAR-H method. Paper presented at the Proceedings of the Human Factors and Ergonomics Society Annual Meeting 52: 1733.

[2] Boyle, P., \& Smith, E.J. (2000). Emergency planning using the HSE's evacuation, escape and rescue (EER) HAZOP technique. In Institution of Chemical Engineers, Symposium Series: Number 147 (pp. 477 - 490). Warwickshire, United Kingdom: Institution of Chemical Engineers.

[3] Canadian Association of Petroleum Producers [CAPP]. (2010). Atlantic Canada Offshore Petroleum Industry Escape, Evacuation and Rescue. Retrieved from <http://www.capp.ca/library/publications/atlanticCanada/pages/pubInfo.aspx?DocId=173688>. Retrieved on July 30, 2017.

[4] Deacon, T., Amyotte, P. R., Khan, F. I., \& MacKinnon, S. (2013). A framework for human error analysis of offshore evacuations. Safety Science, $51,319-327$.

[5] DiMattia, D.G., Khan, F.I., \& Amyotte, P.R. (2005). Determination of human error probabilities for offshore platform musters. Journal of Loss Prevention in the Process Industries, 18, 488-501.

[6] Duarte, E., Rebelo, F., Teles, J., \& Wogalter, M.S. (2014). Behavioral compliance for dynamic versus static signs in an immersive virtual environment. Applied Ergonomics, 45, 1367-1375

[7] Gould, G. W., \& Au, S. Y. Z. (1995). A methodology for hazard identification on EER assessments. In Health and Safety Executives, Offshore Technology Report: 466 (pp. 1- 96). Oxon, United Kingdom: HSE. Retrieved from http://www.hse.gov.uk/research/othpdf/400-499/oth466.pdf. Retrieved on July 10, 2014.

[8] Kennedy, B. (1993). A human factors analysis of evacuation, escape and rescue from offshore installations. Cheshire, United Kingdom: Health and Safety Executive Books.

[9] Khan, F. I., Amyotte, P. R., \& DiMattia, D. G. (2006). HEPI: A new tool for human error probability calculation for offshore operation. Safety Science, 44, $313-334$

[10] Norazahar, N., Khan, F., Veitch, B., \& MacKinnon, S. (2014). Human and organizational factors assessment of the evacuation operation of BP Deepwater Horizon. Safety Science, 70, $41-49$.

[11] Norazahar, N., Khan, F., Veitch, B., \& MacKinnon, S. (2017a). Prioritizing safety critical human and organizational factors of EER systems of offshore installations in a harsh environment. Safety Science, 95, 171-181.

[12] Norazahar, N. (2017b). Risk management of human and organizational factors for the escape and evacuation of offshore installations. Published PhD's thesis. Memorial University of Newfoundland, Canada.

[13] Norazahar, N., Khan, F., Veitch, B., \& MacKinnon, S. (2018a). Dynamic risk assessment of escape and evacuation in a harsh environment. Applied Ocean Research. Manuscript under review.

[14] Norazahar, N., Smith, J., Khan, F., \& Veitch, B. (2018b). The use of a virtual environment in managing risks associated with human responses in emergency situations on offshore installations. Ocean Engineering, 147, 621-628.

[15] OGP, 2010. Risk Assessment Data Directory - Evacuation, Escape \& Rescue (Report No. 434 - 19). London, UK: International Association of Oil and Gas Producers.

[16] Reason, J. (1990). Human error. Cambridge, United Kingdom; Cambridge University Press.

[17] Ren, J., Jenkinson, I., Wang, J., Xiu, D. L., \& Yang, J. B. (2008). A methodology to model causal relationships on offshore safety assessment focusing on human and organizational factors. Journal of Safety Research, 39, 87 - 100.

[18] Skogdalen, J. E. (2011). Risk Management in the Oil and Gas Industry: Integration of Human, Organisational and Technical Factors. Published PhD's thesis. University of Stavanger, Norway.

[19] Skogdalen, J. E., Khorsandi, J., \& Vinnem, J. E. (2012). Evacuation, escape, and rescue experiences from offshore accidents including the Deepwater Horizon. Journal of Loss Prevention in the Process Industries, 25, 148-158.

[20] Trucco, P., Cagno, E., Ruggeri, F., \& Grande, O. (2008). A Bayesian Belief Network modelling of organisational factors in risk analysis: A case study in maritime transportation. Reliability Engineering and System Safety, 93, 823 - 834

[21] Wang, Y. F., Xie, M., Ng, K. M., \& Habibullah, M. S. (2011). Probability analysis of offshore fire by incorporating human and organizational factors. Ocean Engineering, 38, 2042 - 2055

[22] Woodcock, B., \& Au, Z. (2013). Human factors issues in the management of emergency response at high hazard installations. Journal of Loss Prevention in the Process Industries, 26(3), 547-557. 